Case 3 was that of a girl, age 14, the subject of bony tuberculosis. The illness commenced with paralysis of the lower limbs, which extended upwards so that on the fourth day the condition was one of flaccid quadriplegia with abolition of all reflexes, and in addition paralysis of the palate and loss of sphincter control. Intense vulvovaginitis and bronchopneumonia werc also noted during life. The disease terminated fatally in six days. Histological research demonstrated lesions which were necrotic rather than inflamimatory, occupying the anterior horns in the spinal cord. These masses of grey matter appeared to be distended in some places by an exudate from which cellular elements were singularly lacking.

In their discussion of these cases, the authors make it clcar that their conception of Landry's disease is more generous than that commonly accepted in this country. They would include under this heading cvery case of ascending paralysis, distinguishing, first those cases of this condition which are due to an acute peripheral neuritis, and subdividing the cases in which the spinal cord is affected intc poliomyelitis, leucomyclitis (the whitc matter being chiefly involved), and diffuse ascending nyclitis. They point out the striking discrepancies between the histological appearances of the three cases reported, and conclude that it remains for the bacteriologist to establish a more rational classification in this group of discases.

C. P. Symonds.

\title{
CLINICAL PATHOLOGY.
}

[6] Laboratory findings in early and late syphilis: review of one thousand and sixty-four cases.-Fondre and Rosen. Jour. Amer. Med. Assoc., 1921, lxxvii, 1696.

This paper aims at corrclating the scrum and spinal-fluid findings in a large number of cases with the clinical signs and symptoms of the patient. It must never be forgotten that syphilis is a constitutional disease, and signs of neurological and visceral involvement may be discovered if looked for in cases which come up for quite other manifestations of the discase. The authors group as secondary all cases presenting themselves for treatment within two years of the original infection, and as tertiary all others. Of 243 secondary cases 64 , and of 821 tertiary cases 480 had abnormal findings in the spinal fluid. These results showed a higher proportion of positives than normal because they included several eases of obvious neurosyphilis specially sent to the clinic. Elaborate statistical analyses of these figures are given. The cases seem to fall into groups :-

1. Mild reactions with no complaints. These yicld to treatment, and later give negative results.

2. Strong reactions with indetcrminate complaints of headache, giddiness, fatigue, lack of concentration, pains in the limbs, and slight neurological signs such as pupillary changes or incqualities in reflexes. These often resist treatment.

3. Malignant type simulating meningitis and often terminating fatally. These require very small doses of antisyphilitic remedies until the spinal canal has been drained several times to relieve pressure. 
4. Frank neurosyphilis, including the classical vascular and meningovascular forms, gumma, tabes, taboparesis, and paresis. In the pure vascular type the spinal fluid is usually negative, or a few cells and a small amount of globulin may be present. In the meningovascular form the fluid may be negative, yield cells and globulin only, or be positive in all phases. In tabes the picture varies with the activity and stage of the process. In so-called abortive forms the fluid is negative. In carly, active and progressing types it is usually strongly positive, while in the late degenerative types it is frequently negative. In taboparesis the fluid is strongly positive with a paretic curve. In carly untreated cases of paresis a positive fluid was found in $\mathbf{1 0 0}$ per cent of the cases, the cell count ranging from 20 to 250 , a marked increase in globulin, strongly positive Wassermann reaction with $\mathbf{0 . 2}$ c.c. or less, and a paretic curve. In gumma unaccompanied by a meningitis the fluid is usually negative. Psychoses occurring in syphilitics who do not present clinical features of tabes or paresis give a negative fluid.

The authors' statistics show that the incidence of nervous-system involvement is much higher in men than it is in women.

The statement is frequently made that neurosyphilis has increased since the use of the modern antisyphilitic remedies. This increase, in their opinion, is more apparent than real, and is to be attributed to the more systematic investigation of patients and our more thorough knowledge of the discase. There is no proof that arsphenamin adversely affects the optic, auditory, or other cranial nerves ; on the contrary, definite data are furnished showing arrest of optic atrophy by the proper use of the drug. Pupillary anomalies and cranial-nerve paralyses are often pathognomonic and are always suggestive of nervous syphilis. In papillitis and optic neuritis occurring in early syphilis, vision may be normal, with only slight narrowing of the fields. The necessity for routine ophthalmologic examination must, therefore, be emphasized, so that the earliest changes may be detected before irreparable damage is done to the eye. The absence of clinical signs and symptoms does not exclude syphilis of the central nervous system. The classical signs and symptoms of tabes may occur with a negative blood and spinal fluid. Likewise, neurosyphilis of the vascular, gummatous, and other types may present subjective and objective clinical symptoms with an excess of globulin only in the fluid.

The colloidal-gold reaction has been employed by the authors for six years. They consider it of great diagnostic and prognostic value. A luetic curve enables them with almost absolute certainty to exclude paresis. A paretic curve is always present in paresis in untreated cases, but may be encountered in meningovascular syphilis and may disappear under treatment. A paretic curve is also found in some types of early neurosyphilis, and disappears as the other phases become negative.

R. G. Gondox.

[千] Neurosyphilis with negative spinal fluid.-Solovion and Klacder. Jour. Amer. Med. Assoc., 1921, Ixxvii, 1701.

TuE authors point out that neurosyphilis may exist without positive 
findings in the cerebrospinal fluid. In addition to purely vascular syphilis, which only gives positive findings in the fluid if there is marked inflammatory reaction round the vessels, negative findings may occur in tabes, ccrebral gumma, syphilitic cercbral nerve palsies, Erb's spastic paralysis. paraplegia, epilepsy, paranoia, and dementia. They regard the Argyll Robertson pupil as being pathognomonic of syphilis, and consider that the experieneed neurologist may diagnose neurosyphilis from various characteristic combinations of symptoms in the absence of laboratory findings. The general opinion is that positive findings in the fluid exist for many years before symptoms are manifested, but exceptions may occur, and some believe that syphilis confined to the brain always gives negative fluid findings. It has been shown that the gold reaction varies in the same patient according as the fluid is taken from the ventricle, the cisterna magna, or the lumbar sas.

Cases of tabes with negative findings include (1) cases of incipient progressive type, (2) cases in which pathological findings have disappeared after treatment, (3) abortive tabes. Case notes are given of all types of neurosyphilis with negative fluid findings.

R. G. Gordon.

\section{SYMPTOMATOLOGY.}

[8] Two cases of cerebrospinal cysticercus infection with chronic meningitis and endarteritis of the brain (Deux cas de cysticercose cérébro-spinaic avec méningite chronique et endartérite obliterante cérébrale).--L. Redalie. Revue neurcl., 1921, xxxvii, 241.

Tile two cases may be summarized as follows. The first was that of a woman, age 54, with a nine months' histery of headaches and pains in the back, and oceasional attacks of vertigo without loss of consciousness. Some weeks hefore death there developed retention of urine, constipation, paralysis of the limbs, paresis and dilatation of the left pupil, disturbances of sensibility, exaggeration of the deep reflexes, and extensor plantar responses. The intellert failed, there was swelling of the optic discs and a positive Kernig's sign, and finally the patient died with bed-sores and cystitis. Lumbar puncture some weeks before death showed an increase of albumin, 210 cells per c.mm., and a positive Wassermann reaction. ;

At the autopsy there appeared to be a considerable degrec of internal hydroccphalus and a chronic leptomeningitis affecting mainly the base of the brain and the cervical region of the cord. Histological examination showed structures rescmbling the cysts of cysticercus in the neninges of the ventral surfaces of the pons and of the cervical cord, and an obliterative endarteritis of the large and medium-sized vessels at the base of the brain.

The sccond case was that of a man, age 66, who had suffered for fifteen years from epilepsy and for some months had noticed difficulty in walking. He was admitted to hospital with a diagnosis of multiple cerebral thrombosis. 'Ihe Wassermann vas negative in the blood, positive in the spinal fluid; the latter contained at that time 3.2 cells per c.mm. 